\title{
Undervaluation of Radiotherapy for Gross Desmoid Tumors: The Need for Absolute Volume Assessment
}

\author{
YEON JOO KIM ${ }^{1}$, SI YEOL SONG ${ }^{1}$, WANLIM KIM ${ }^{2}$, JONGSEOK LEE ${ }^{2}$, JIN-HEE AHN ${ }^{3}$, \\ JEONG EUN KIM ${ }^{3}$, HYE WON CHUNG ${ }^{4}$, SEONG-YUN JEONG ${ }^{5}$ and EUN KYUNG CHOI ${ }^{1}$ \\ Departments of ${ }^{1}$ Radiation Oncology, ${ }^{2}$ Orthopedic Surgery, ${ }^{3}$ Internal Medicine, and \\ ${ }^{4}$ Radiology, Asan Medical Center, University of Ulsan College of Medicine, Seoul, Republic of Korea; \\ ${ }^{5}$ Asan Cancer Institute, Seoul, Republic of Korea
}

\begin{abstract}
Background/Aim: To compare absolute volume $(A V)$ assessment according to Response Evaluation Criteria in Solid Tumors (RECIST) for the response evaluation of desmoid tumors (DTs) treated with radiotherapy. Patients and Methods: Eighteen patients with DTs $\geq 3 \mathrm{~cm}$ in size were included. Results: The median follow-up duration was 78.0 months. Five patients achieved a complete response according to RECIST, seven reached a partial response (PR), and one eventually exhibited progression. The overall response rate was $61 \%$, the median time to $P R$ was 8.0 months. Six patients achieved stable disease, although three developed progressions. Of the six patients with a PR, the median change in maximum diameter was $-46 \%$, and the median change in maximum volume was $-84 \%$. Three patients could have been diagnosed with progression at least 6 months earlier if the $A V$ increment was considered. Conclusion: An AV assessment is essential for an accurate response assessment of DTs and radiotherapy seems feasible as a first-line treatment for DTs.
\end{abstract}

A desmoid tumor (DT), which is also known as an aggressive fibromatosis, is a rare, locally aggressive, benign soft-tissue tumor that is characterized by monoclonal fibroblastic proliferation (1). A DT can arise as a solid tumor from muscles in the extremities, trunk, and abdomen, or as a diffuse tumor in the mesentery (2). Although DTs do not metastasize to

This article is freely accessible online.

Correspondence to: Si Yeol Song, MD, Ph.D., Professor, Department of Radiation Oncology, Asan Medical Center, University of Ulsan College of Medicine, 88 Olympic-ro 43-gil, Songpa-gu, Seoul 05505, Republic of Korea. Tel: +82 230104431, Fax: +82 230106950, e-mail: siyeol.song@gmail.com

Key Words: Desmoid tumor, radiotherapy, response assessment, absolute volume, RECIST. distant sites, these tumors are associated with a high risk of local relapse even after surgical resection with negative margins. Patients with DTs are generally asymptomatic but may complain about various symptoms caused by the compressive or obstructive effects of the tumors.

Historically, surgical resection has been the first-line therapy for DT. However, the recent guideline from the European Desmoid Working Group no longer recommends immediate surgery as the standard-of-care (3). DTs may regress spontaneously in up to $20 \%$ of cases $(4,5)$, and therefore watchful waiting can be a reasonable option for asymptomatic tumors that are not located in regions where functional limitations might arise due to tumor progression. However, several treatment options [e.g., surgery, radiotherapy (RT), systemic therapy] can be considered for tumors that are symptomatic or have increased in size. Definitive RT is recommended for symptomatic patients when surgical resection is impossible or would be expected to cause severe functional impairment. RT can also be administered if microscopic or macroscopic residual disease is detected after surgery $(6,7)$. Salvage RT is also commonly performed for recurrent DT after repeated resection surgeries.

Few clinical studies have reported the results of definitive or salvage RT for gross DTs (8-10). However, the effects of these approaches have been undervalued by most surgeons or physicians because of the slow course of tumor regression and risk of adverse effects. A recent phase II pilot study that used the Response Evaluation Criteria in Solid Tumors (RECIST) to evaluate tumor responses reported that only half of the patients exhibited a complete $(\mathrm{CR})$ or partial response (PR) during the first 3 years (8). We suspected that the perception that DTs respond slowly after RT might be influenced by the existing one-dimensional RECIST criteria, which are more suitable for regularly shaped tumors. Frequently, DTs are not spherical but feature irregular shapes with extensions along the fascial planes. In a previous study that compared the RECIST and tumor volume changes in the context of a response assessment for soft-tissue sarcoma after 
preoperative RT, $80 \%$ of tumors exhibited a reduction in volume to some degree that may have facilitated surgical resection (11). Likewise, we hypothesized that the absolute volume assessment would be more suitable than RECIST for detecting early responses and progression in DTs.

In this retrospective study, we aimed to determine the value of an absolute volume assessment after RT for DT and to compare this assessment with the existing RECIST, using the longest axial diameter. We additionally evaluated the outcomes of gross DTs treated with RT.

\section{Patients and Methods}

Patients who were diagnosed and treated with RT for DT between July 2001 and July 2018 were identified by searching our institutional database. A total of 51 patients were identified. The response evaluation included patients with gross tumor(s) larger than $3 \mathrm{~cm}$ before RT. Twenty-eight patients who underwent surgery that resulted in an R0/1 resection and two patients with residual tumors smaller than $3 \mathrm{~cm}$ after surgery were excluded. Three patients with diseases involving multiple mesentery or visceral organs were also excluded. Finally, 18 patients were enrolled in the evaluation. Their clinical data were obtained through a retrospective review. The local institutional review board waived the requirement for informed consent before the analysis.

The patients' characteristics are listed in Table I. The majority $(72 \%)$ was female, and the median age was 44 years (range $=22-58$ years). The thorax (33\%) was the most common site of DT involvement, followed by the neck (22\%), abdomino-pelvic area $(22 \%)$, and lower extremities (17\%). The median longest diameter and total volume were $7.4 \mathrm{~cm}($ range $=3.3-13.2 \mathrm{~cm})$ and $88.0 \mathrm{~cm} 3$ (range=9.3-974.7 $\mathrm{cm}^{3}$ ), respectively. Ten patients had received the first diagnosis of DT. Among them, five patients were treated with definitive RT alone, and the others underwent surgery that resulted in $\mathrm{R} 2$ resection with a residual tumor size $>3 \mathrm{~cm}$. Three of these patients also received chemotherapy $(n=1)$ or tamoxifen $(n=2)$ before operation. Eight patients were diagnosed with recurrent disease after undergoing surgery and/or chemotherapy or radiofrequency ablation as the initial therapy. After a diagnosis of recurrence, three patients were initially treated with chemotherapy alone $(n=2)$ or with chemotherapy and tamoxifen $(n=1)$.

Patients who received RT underwent 3-dimensional conformal RT (3D-CRT; $n=12$ ), intensity-modulated RT (IMRT; n=5), or volumetric arc therapy (VMAT; $\mathrm{n}=1$ ). Planning computed tomography $(\mathrm{CT})$ was obtained using a CT scanner with a slice thickness of $2.5 \mathrm{~mm}$. For 3D-CRT and IMRT, the patients were irradiated with 4,6 , or $15 \mathrm{MV}$ photon beams from two to nine directions. The clinical target volume covered a $2-5 \mathrm{~cm}$-margin beyond the gross tumor and was adapted to anatomic barriers such as the same muscle compartment. The planning target volume (PTV) margins ranged from 0.5 to $1.0 \mathrm{~cm}$. In nine patients, the radiation field was reduced for a boost irradiation dose of 12-26 Gy. The reduced PTV was calculated as an expansion of the gross tumor volume with margins of 0.7 and $1.0 \mathrm{~cm}$. The median RT dose was 55 Gy (range=40-66 Gy) with a median fraction size of 2 Gy (range $=1.8-3 \mathrm{~Gy}$ ) (Table I).

Patients were followed up at 1-4 months after treatment and every 6-12 months thereafter, according to the physician's decision.
Table I. Characteristics and treatment data of the included patients $(n=18)$

\begin{tabular}{lc}
\hline & Number $(\%)$ \\
\hline Gender & \\
Male & $5(28)$ \\
Female & $13(72)$ \\
Age & \\
Median, years (range) & $44(22-58)$ \\
Involved site & \\
Neck & $4(22)$ \\
Thorax & $6(33)$ \\
Abdomino-pelvic & $4(22)$ \\
Upper extremity & $1(6)$ \\
Lower extremity & $3(17)$ \\
Number of tumor(s) & $17(94)$ \\
1 & $1(6)$ \\
2 & \\
Longest axial diameter of tumor(s) before RT & $7.4(3.3-13.2)$ \\
Median, cm (range) & $10(56)$ \\
$3-8$ cm & $8(44)$ \\
$>8$ cm & \\
Volume of tumor(s) before RT & $88.0(9.3-974.7)$ \\
Median, cc (range) & \\
Disease status before RT & $5(28)$ \\
Initial, no surgery & $5(28)$ \\
Initial, R2 resection & $6(33)$ \\
Recurrent, no surgery & $2(11)$ \\
Recurrent, R2 resection & \\
Medical treatment before RT and/or surgery & $3(17)$ \\
Yes, chemotherapy & $2(11)$ \\
Yes, tamoxifen & $12(67)$ \\
Yes, Both & \\
No & $55(40-66)$ \\
RT dose & \\
Median, Gy (range) & \\
Fraction size & $(1.8-3)$ \\
Median, Gy (range) & \\
\hline
\end{tabular}

RT: Radiotherapy.

The imaging studies included ultrasonography (US), CT, or magnetic resonance imaging (MRI) of the irradiated site. As an absolute volume assessment was required, only CT and MRI data were included in the analyses. All patients were followed for a minimum of 8 months and underwent two or more follow-up imaging studies at different times. The maximum diameter and absolute volume were measured by two experienced radiation oncologists who agreed on the results. For absolute volume measurement, images were imported into the treatment planning system (TPS) of Eclipse (Eclipse 13.6, Varian Medical Systems, Palo Alto, CA, USA) and tumor volumes were contoured, then the TPS calculated the absolute volume of tumors.

The RECIST version 1.1 was utilized. These criteria define a CR as the disappearance of all target lesions, and a PR as a decrease of $\geq 30 \%$ in the sum of the target lesions diameters. Progressive disease (PD) is defined as an increase of $\geq 20 \%$ in the sum of the target lesions diameters. Stable disease (SD) is defined as neither sufficient shrinkage to qualify as PR nor sufficient growth to qualify as PD. 


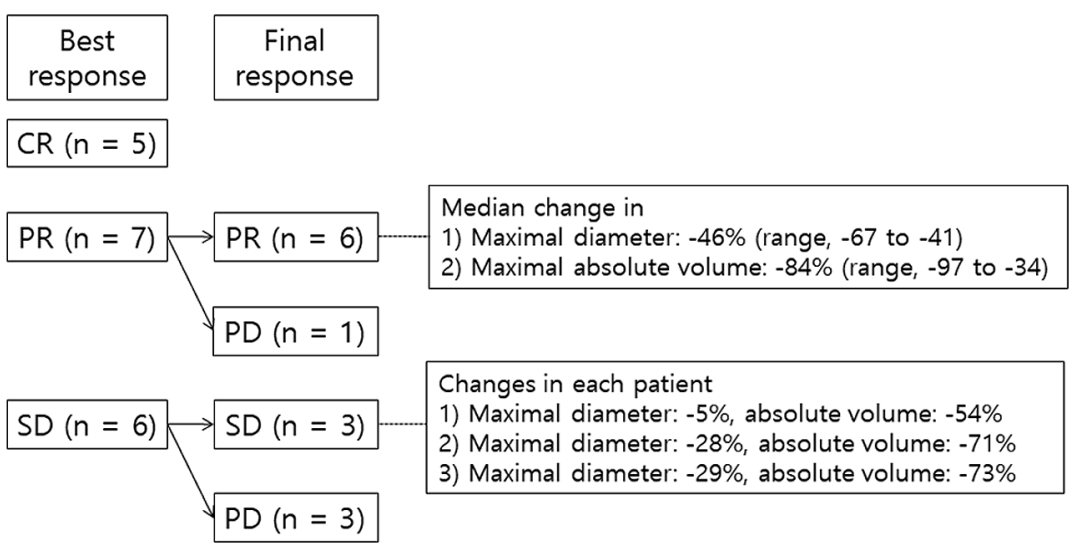

Figure 1. Best and final responses of the included patients (n=18) according to the Response Evaluation Criteria in Solid Tumors (RECIST) version 1.1.

Because the study was mainly focused on the responses in the irradiated area, only the diameter and volume of the irradiated lesion(s) were measured for the response assessment. The appearance of new lesions outside the radiation field was considered separately as out-field recurrences and did not affect the response evaluation.

Secondarily, the 5-year in-field progression-free survival (IFPFS), out-field progression-free survival (OFPFS), and toxicity rates were evaluated. Acute and late toxicities were evaluated using the Common Terminology Criteria for Adverse Events version 4.03. Acute toxicities were defined as adverse events that occurred within 3 months after the completion of RT. Local regression in R software was used to compare the volume and maximum diameter changes. The Kaplan-Meier method was used to estimate survival outcomes. A univariate analysis was performed using the log-rank test. All statistical tests were two-sided, and a $p$-value of $<0.05$ was considered statistically significant. MedCalc Statistical Software version 14.8.1 (MedCalc Software Bvba, Ostend, Belgium) and R version 3.6.0 (R Foundation for Statistical Computing, Vienna, Austria) were used for the analyses.

\section{Results}

The median follow-up duration was 78.0 months (range=8.6217.8 months) from the last date of RT. For all 18 patients, data from six to eight follow-up MRI and 31 follow-up CT scans were analyzed. A median of 5 (range=2-12) imaging studies were performed per patient.

Assessment according to the RECIST 1.1. Figure 1 summarizes the responses of the 18 patients. Five patients achieved a CR. The time to CR was 44 months in two patients, 51 months in two patients, and 96 months in one patient. Seven patients met the criteria for PR, although one developed PD at 22 months. The final overall response rate was $61 \%(11 / 18)$, and the median time to PR among responders was 8.0 months (range=0.8-38.4 months). Five patients initially achieved SD, and three later developed PD. In the four patients with $\mathrm{PD}$, the time to progression ranged from 18 to 22 months.

Comparisons between the changes in the maximum diameter and absolute volume. In six patients who ultimately achieved a PR, the median change in the maximum diameter was $-46 \%$ (range $=-67 \%$ to $-41 \%$ ), and the median change in the maximum volume was $-84 \%$ (range $=-97 \%$ to $-34 \%$; Figure 1). None of the three SD patients demonstrated an increase in tumor diameter or volume. In these three patients, the maximum diameter changes were $-5 \%,-28 \%$, and $-29 \%$, while the corresponding maximum absolute volume changes were $-54 \%,-71 \%$, and $-73 \%$, respectively.

Figure $2 \mathrm{~A}$ presents the local regression curves of the percent changes in the maximum axial diameters and absolute volumes in 14 patients who finally achieved a response or SD during the first 30 months after treatment. Most responses and progressions occurred during this period, and there were fewer differences in the number of imaging studies in each patient. The results demonstrate that the absolute volume change was persistently much more drastic than the change in diameter.

Of the four patients who demonstrated progression, three might have been diagnosed as PD earlier if a volumetric assessment were performed. The first patient could have been diagnosed as PD 8 months earlier using a volumetric assessment, as the absolute volume increased by 1.64 times relative to the previous volume, whereas only a $+5 \%$ change in the maximum axial diameter was observed. The second patient exhibited an increase of $240 \%$ in the initial tumor volume without a significant diameter change at 13 months, whereas the diameter had increased by $>30 \%$ at 20 months. The third patient could have been diagnosed as PD 6 months 

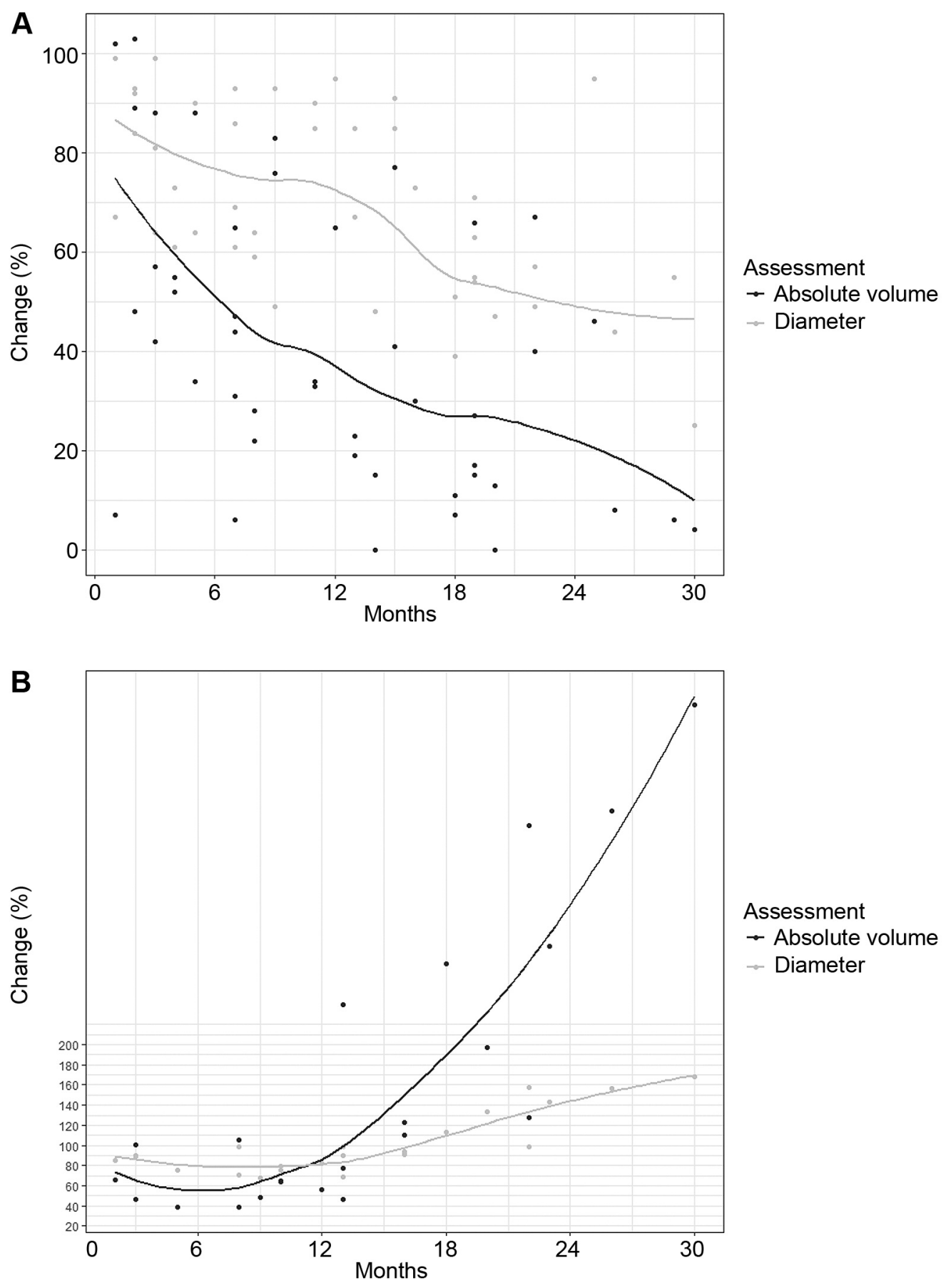

Figure 2. Local regression curves of the percent changes in the maximum axial diameter and absolute volume in (A) patients who finally achieved a response or stable disease $(n=14)$ and $(B)$ those who developed progressive disease $(n=4)$.

earlier because the volume had increased by $72 \%$, whereas the diameter only increased by $+18 \%$.

Figure 2B presents the local regression curves of the percent changes in the maximum axial diameters and absolute volumes during the first 30 months in four patients who exhibited PD. Although minimal changes in diameter were observed in the first year, the absolute volumes decreased slightly and then began to increase after 6 months. 
Similarly, the volume changes were more drastic than the diameter changes in non-PD patients.

Progression-free survival and characteristics of patients with $P D$. The 18 patients had a 5-year IFPFS rate of $73.3 \%$ (Figure 3A). In-field progression occurred in four patients, and their characteristics are listed in Table II. Three of these patients were aged 20-29 years and had the largest tumor diameters $>6 \mathrm{~cm}$. However, two of these patients had relatively small tumor volumes of 20.8 and $29.5 \mathrm{~cm} 3$. Two patients received total RT doses <55 Gy. The 5-year OFPFS rate in the whole sample was $83.3 \%$ (Figure 3B), and two patients experienced out-field recurrences without in-field recurrences. All patients remained alive at the last follow-up. Univariate analyses were performed to identify potential factors related to IFPFS, and OFPFS did not identify any significant factors that affected survival.

Toxicity. Of the 18 patients, one experienced grade 2 acute radiation dermatitis and six $(33 \%)$ developed grade 1 acute radiation dermatitis. Two patients experienced grade 1 acute lymphedema. There were no grade $\geq 3$ acute toxicities. Regarding late toxicities, three patients developed grade 1 radiation fibrosis, and none developed grade $\geq 2$ events.

\section{Discussion}

In this study, we compared the absolute volume assessment with the traditional response assessment system based on the maximum diameter and RECIST 1.1 in a sample of patients with DT after RT. We hypothesized that the absolute volume assessment would be more sensitive than RECIST, which is associated with the risk of response underestimation. As expected, the RECIST tended to underestimate the absolute volume changes. Sixty-one percent of the patients were classified as responders, and the median time to PR was 8 months. This slow response according to RECIST suggested that RT had a limited effect on DTs. Additionally, three patients who achieved SD exhibited approximately $50 \%$ reductions in tumor volume after RT, but these cases were not identified as responders when using the RECIST criteria.

According to the local regression curve in Figure 2A, the absolute volume change decreased to $\sim 51 \%$ of the initial volume at 6 months and decreased further to $\sim 37 \%$ at 12 months in patients who ultimately achieved a PR or SD $(\mathrm{n}=14)$. However, the maximum diameter decreased to only $\sim 77 \%$ of the initial diameter at 6 months and remained at $\sim 72 \%$ of the initial value at 1 year.

The results suggest that an absolute volumetric assessment should be adopted for an accurate DT response evaluation and that an adequate cut-off value for responders is needed. The European Pediatric Soft-Tissue Sarcoma Study Group
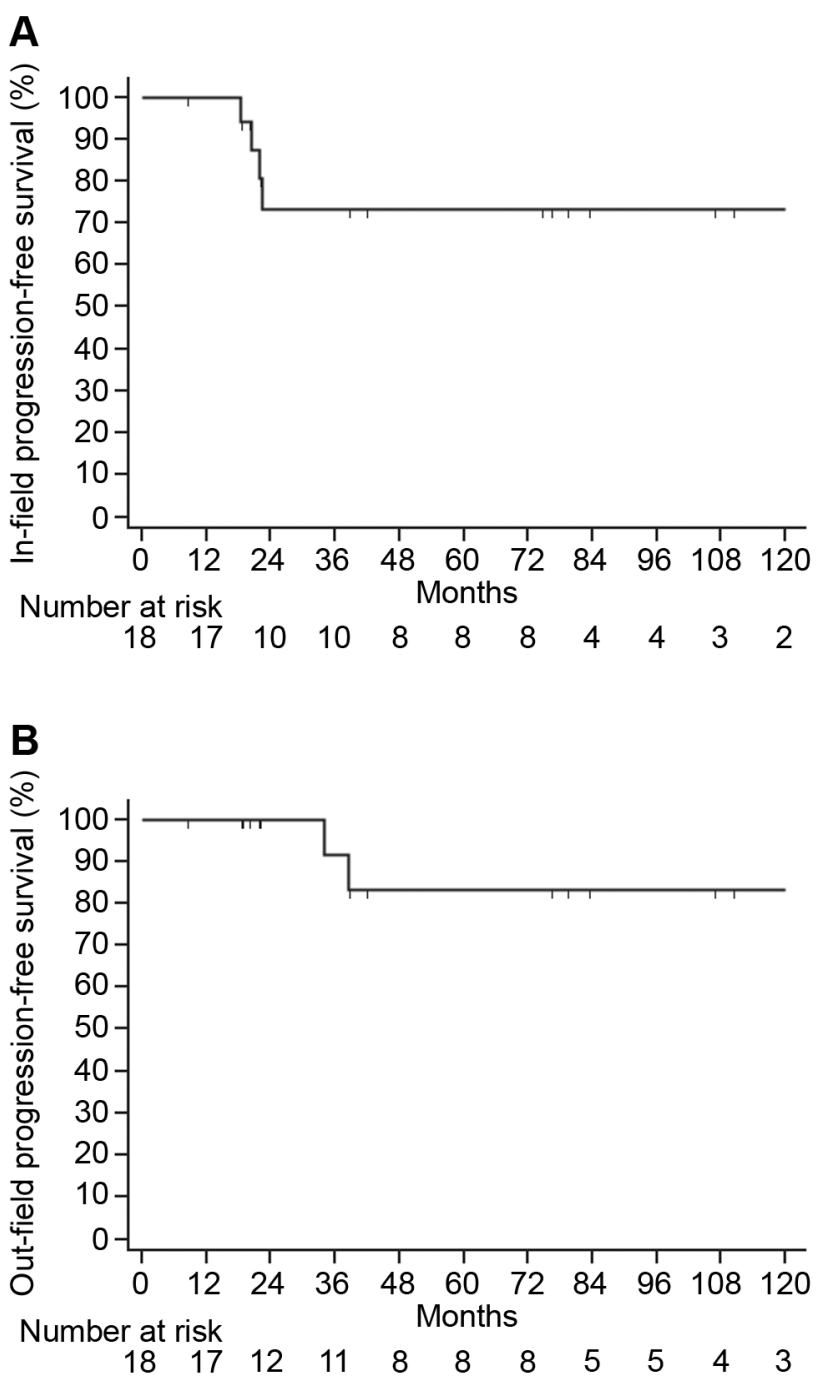

Figure 3. Five-year survival curves for (A) in-field progression-free survival and $(B)$ out-field progression-free survival.

(EpSSG) suggested a three-dimensional measurement guideline for soft-tissue tumors and defined a major PR (reduction by $66 \%-99 \%$ ) using measures extrapolated from the PR criteria in the RECIST. This group also included the concept of a minor PR, defined as a reduction by $34-65 \%$ (12). A cut-off value of $34 \%$ for a minor PR seemed to be reasonable as this may reflect an early response and could be used to detect responders earlier than 6 months. When the EpSSG criteria were applied to the present cohort, 17 patients had achieved a minor PR, and the median time to minor PR was 5 months (range $=1-22$ months). Furthermore, three patients (18\%) ultimately exhibited PD at 18-22 months. None of the 11 patients who achieved a major PR later developed PD. The median time to a major PR was 13 months (range $=7-47$ months). 
Table II. Details of patients who developed in-field progression.

\begin{tabular}{lcccccc}
\hline No. & Gender & $\begin{array}{c}\text { Age, } \\
\text { years }\end{array}$ & Involved site & $\begin{array}{c}\text { Longest axial } \\
\text { diameter, cm }\end{array}$ & $\begin{array}{c}\text { Volume, } \\
\mathrm{ml}\end{array}$ & $\begin{array}{c}\text { Disease status } \\
\text { before RT }\end{array}$ \\
\hline 1 & Male & 25 & Right neck & 8.1 & 20.8 & Initial, R2 resection \\
2 & Female & 27 & Lt common iliac & 7.2 & 345.9 & Initial, no surgery \\
Gy \\
3 & Male & 28 & Right neck & 6.2 & 29.5 & $\begin{array}{c}\text { Recurrent, R2 resection } \\
\text { Recurrent, R2 resection }\end{array}$ \\
4 & Female & 58 & Upper back & 10.6 & 504.4 & 50.4 \\
\hline
\end{tabular}

RT: Radiotherapy.

Table III. Summary of previous reports on the treatment results of gross desmoid tumors treated with radiotherapy.

\begin{tabular}{|c|c|c|c|c|c|c|c|c|c|c|c|}
\hline Study & Type & Period & $\mathrm{N}$ & $\begin{array}{l}\text { Gender } \\
(\%)\end{array}$ & $\begin{array}{l}\text { Median } \\
\text { age, } Y\end{array}$ & $\begin{array}{c}\text { Median } \\
\text { diameter, } \mathrm{cm}\end{array}$ & $\begin{array}{l}\text { Status } \\
(\%)\end{array}$ & $\begin{array}{l}\text { Dose }(\mathrm{Gy}) / \\
\text { fraction size }\end{array}$ & $\begin{array}{c}\text { Median } \\
\text { f/u, M }\end{array}$ & $\begin{array}{l}\text { IFPFS } \\
(\%)\end{array}$ & Toxicity \\
\hline $\begin{array}{l}\text { Santti et al. } \\
\text { (19) (2017) }\end{array}$ & $\mathrm{R}$ & $1987-2012$ & 22 & $\begin{array}{l}\mathrm{M}(68)^{\dagger} \\
\mathrm{F}(32)\end{array}$ & $45^{*}$ & NA & NA & $\begin{array}{c}20-63 \\
(\text { median } 50) / \\
1.8-2.1\end{array}$ & $84^{\dagger}$ & $62(5 \mathrm{Y})$ & NA \\
\hline $\begin{array}{l}\text { Keus et al. } \\
\text { (8) (2013) }\end{array}$ & $\mathrm{P}$ & 2001-2008 & 44 & $\begin{array}{l}\text { M (39) } \\
\text { F (61) }\end{array}$ & 40 & $\begin{array}{c}\text { NA, but } 42 \% \text { had } \\
\text { tumor sized } \\
4-8 \mathrm{~cm}\end{array}$ & $\begin{array}{c}\text { Primary (61) } \\
\text { Recurrent (39) }\end{array}$ & $56 / 2$ & 58 & $81.5(3 \mathrm{Y})$ & $\begin{array}{c}\text { Acute } \geq \mathrm{G} 3 \text { : } \\
\text { limited to skin, } \\
\text { mucosa, pain } \\
\text { Late } \geq \mathrm{G} 3 \text { : skin } \\
\text { (2 cases) }\end{array}$ \\
\hline $\begin{array}{l}\text { Spear } \text { et al. } \\
\text { (10) (1998) }\end{array}$ & $\mathrm{R}$ & 1971-1992 & 15 & $\begin{array}{l}\text { M (26) } \\
\text { F (74) }\end{array}$ & $29 *$ & 7 & $\begin{array}{l}\text { Primary (33) } \\
\text { Recurrent (67) }\end{array}$ & $\begin{array}{l}45-75 / \\
1.8-2^{\dagger}\end{array}$ & $>60$ & $93(5 \mathrm{Y})$ & NA \\
\hline $\begin{array}{l}\text { Ballo et al. } \\
\text { (17) (1998) }\end{array}$ & $\mathrm{R}$ & 1965-1994 & 23 & $\begin{array}{l}M(45) \\
F(55)^{\dagger}\end{array}$ & $28^{\dagger}$ & $7^{\dagger}$ & $\begin{array}{l}\text { Primary }(28)^{\dagger} \\
\text { Recurrent (72) }\end{array}$ & $\begin{array}{l}\text { Mainly } \\
55 / 2\end{array}$ & $90^{\dagger}$ & $69(5 \mathrm{Y})$ & $\mathrm{No} \geq \mathrm{G} 3$ \\
\hline $\begin{array}{l}\text { Acker } \text { et al. } \\
\text { (18) (1993) }\end{array}$ & $\mathrm{R}$ & $1974-1990$ & 16 & $\begin{array}{l}\mathrm{M}(38) \\
\mathrm{F}(62)^{\dagger}\end{array}$ & $28^{\dagger}$ & $9.3^{*}$ & $\begin{array}{c}\text { Primary (13) } \\
\text { Recurrent (87) }\end{array}$ & $54 / 1.7-2$ & 58 & $94(5 \mathrm{Y})$ & NA \\
\hline Current & $\mathrm{R}$ & $2001-2018$ & 18 & $\begin{array}{l}\text { M (28) } \\
\text { F (72) }\end{array}$ & 44 & 7.4 & $\begin{array}{l}\text { Primary (56) } \\
\text { Recurrent (44) }\end{array}$ & $\begin{array}{l}\text { Median } \\
55 / 2\end{array}$ & 78 & $73(5 Y)$ & $\begin{array}{c}\text { Acute: } \text { no } \geq \mathrm{G} 3 \\
\text { Late: no } \geq \mathrm{G} 2\end{array}$ \\
\hline
\end{tabular}

f/u: Follow-up; G: grade; IFPFS: in-field progression-free survival; M: months; N: number: NA: not available; P: prospective; R: retrospective; RT: radiotherapy; Y: year. *Provided as a mean value. †Information provided for the whole study population, including patients who underwent surgery.

It seems that the achievement of a minor PR, according to the EpSSG definition, within 6 months could be an early marker of a good prognosis after RT. However, this achievement does not guarantee further regression, as indicated by the $18 \%$ of the patients who experienced a PD at 2 years. Regular imaging follow-ups for a minimum of 2 years would be essential for detecting in-field progression. Additionally, outfield recurrence seems to occur later than in-field progression, suggesting that a further follow-up duration of approximately 3 years would be needed. The adoption of the EpSSG definition of PD as a $\geq 40 \%$ increase in the tumor volume would be a helpful and sensitive measure for detecting PD. The use of these criteria would have allowed three cases of PD to have been detected 6-8 months earlier.

Alternative measures of response other than the tumor volume have also been suggested $(13,14)$. One retrospective study proposed that the T2-weighted signal on MRI might be a superior imaging biomarker, as this type of signal intensity indicated a biologic transformation from a tumor to a collagenous scar (15). A recent article proposed a response assessment that included changes in attenuation on $\mathrm{CT}$ or signal intensity on MRI (16). Quantification of the changes using a radiomics approach might improve response evaluation and is worthwhile to study, however, our study had a limited power for analyses of radiomics because of the heterogeneity and low number of imaging studies.

Our study demonstrated fair 5-year IFPFS (73.3\%) and OFPFS rates $(83.3 \%)$. These results were comparable to those of previous studies in which the IFPFS ranged from $62 \%$ to $94 \%(8,10,17-19)$ (Table III). In a comparative review of 22 studies, radiation doses between 50 and $60 \mathrm{~Gy}$ led to a favorable local control rate of $83 \%$ during an overall median follow-up time of 6 years (9). The reported toxicities were minimal, with few grade $\geq 3$ complications.

Systemic treatment options, including antihormonal therapies (e.g., tamoxifen) and non-steroidal anti-inflammatory 
drugs, have also been administered to patients with unresectable, recurrent, or progressing DTs, and reports suggest that anti-estrogen therapy yielded effects in approximately half of the evaluated patients (20). However, a recent study found no clear relationship between changes in the symptoms, sizes, or MRI signals of DTs after anti-estrogen therapy (21), and therefore the European Desmoid Working Group does not recommend this treatment (2). Tyrosine kinase inhibitors such as imatinib and sorafenib have also been used. A phase III trial demonstrated that patients with progressive, symptomatic, or recurrent DTs had a prolonged PFS with sorafenib use relative to a placebo (5). That study reported 2year PFS of $81 \%$ during a median follow-up of 27 months. However, almost half of the patients in the sorafenib arm experienced grade $\geq 3$ toxicities. We cautiously assert that RT is a more appropriate treatment option for localized DTs, as the outcomes were comparable to those associated with surgery or systemic agent therapy, with a low incidence of severe toxicities. A randomized phase III study is urgently needed to provide robust evidence in support of RT.

This study has several limitations. First, the number of patients was small $(n=18)$ because of the rarity of the disease. Second, the follow-up imaging modalities were heterogeneous, and sometimes included US, MRI, and CT even for the same patient. We excluded US imaging data from the analyses, which led to missing data for some patients. Differences in the measured tumor volumes and diameters between the imaging modalities might have affected the accuracy of the response assessment. Third, the patient follow-up durations were highly variable. This resulted in differences in the number of imaging studies per patient, and we therefore evaluated changes in the tumor diameter and volume only within the first 30 months. The responses and toxicity events might be underestimated in patients with a short follow-up duration. Fourth, we included patients over a long period, and developments in treatments over time might have led to undetectable bias. Finally, this was a retrospective study, and little clinical response information was available regarding symptom improvements. Despite these limitations, our data provide precise information about the changes in the absolute volumes and diameters of measurable DTs after RT and the related survival outcomes.

In conclusion, an absolute volume assessment is strongly required for an accurate response assessment of a DT, as the RECIST cannot sensitively reflect the tumor responses and can lead to underestimation. Furthermore, efforts are needed to establish RT as a first-line treatment for DT.

\section{Conflicts of Interest}

None of the authors have any conflicts of interest and they have no relevant financial relationships.

\section{Authors' Contributions}

SYS conceived and designed the study. YJK collected the data. WK, JL, JA, and JEK contributed data and performed the data analysis and interpretation. YJK wrote the paper, and HWC, SJ, and EKC provided revisions to the scientific and statistical content of the manuscript.

\section{Acknowledgements}

This work was supported by the National Research Foundation (NRF) grant funded by the Korean government (NRF2018R1D1A1B07049970), and the Basic Science Research Program through the NRF funded by the Ministry of Education (NRF2017R1D1A1B03035167).

\section{References}

1 Jo VY and Fletcher CD: WHO classification of soft tissue tumours: An update based on the 2013 (4th) edition. Pathology 46(2): 95104, 2014. PMID: 24378391. DOI: 10.1097/PAT.000000 0000000050

2 Kasper B, Ströbel P and Hohenberger P: Desmoid tumors: Clinical features and treatment options for advanced disease. Oncologist 16(5): 682-693, 2011. PMID: 21478276. DOI: 10.1634/theoncologist.2010-0281

3 Kasper B, Baumgarten C, Garcia J, Bonvalot S, Haas R, Haller F, Hohenberger P, Penel N, Messiou C, van der Graaf WT, Gronchi A and Desmoid Working Group: An update on the management of sporadic desmoid-type fibromatosis: A European consensus initiative between sarcoma patients euronet (SPAEN) and European organization for research and treatment of cancer (EORTC)/soft tissue and bone sarcoma group (STBSG). Ann Oncol 28(10): 2399-2408, 2017. PMID: 28961825. DOI: 10.1093/annonc/mdx323

4 Bonvalot $\mathrm{S}$, Ternès N, Fiore M, Bitsakou G, Colombo C, Honoré C, Marrari A, Le Cesne A, Perrone F, Dunant A and Gronchi A: Spontaneous regression of primary abdominal wall desmoid tumors: More common than previously thought. Ann Surg Oncol 20(13): 4096-4102, 2013. PMID: 24052312. DOI: 10.1245/ s10434-013-3197-x

5 Gounder MM, Mahoney MR, Van Tine BA, Ravi V, Attia S, Deshpande HA, Gupta AA, Milhem MM, Conry RM, Movva S, Pishvaian MJ, Riedel RF, Sabagh T, Tap WD, Horvat N, Basch E, Schwartz LH, Maki RG, Agaram NP, Lefkowitz RA, Mazaheri Y, Yamashita R, Wright JJ, Dueck AC and Schwartz GK: Sorafenib for advanced and refractory desmoid tumors. N Engl J Med 379(25): 2417-2428, 2018. PMID: 30575484. DOI: 10.1056/NEJMoa1805052

6 Choi SH, Yoon HI, Kim SH, Kim SK, Shin KH and Suh CO: Optimal radiotherapy strategy for primary or recurrent fibromatosis and long-term results. PLoS One 13(5): e0198134, 2018. PMID: 29813130. DOI: 10.1371/journal. pone. 0198134

7 Kim JS, Kim HJ, Lee MY, Moon KC, Song SG, Kim HS, Han I and Kim IH: Survival outcomes after adjuvant radiotherapy for aggressive fibromatosis depend on time frame and nuclear $\beta$ catenin. Radiat Oncol J 37(1): 37-42, 2019. PMID: 30947479. DOI: $10.3857 /$ roj.2018.00542 
8 Keus RB, Nout RA, Blay JY, de Jong JM, Hennig I, Saran F, Hartmann JT, Sunyach MP, Gwyther SJ, Ouali M, Kirkpatrick A, Poortmans PM, Hogendoorn PCW and van der Graaf WTA: Results of a phase II pilot study of moderate dose radiotherapy for inoperable desmoid-type fibromatosis - an EORTC STBSG and ROG study (EORTC 62991-22998). Ann Oncol 24(10): 2672-2676, 2013. PMID: 23868907. DOI: 10.1093/annonc/ mdt 254

9 Nuyttens JJ, Rust PF, Thomas CR Jr and Turrisi AT 3rd: Surgery versus radiation therapy for patients with aggressive fibromatosis or desmoid tumors: A comparative review of 22 articles. Cancer 88(7): 1517-1523, 2000. PMID: 10738207.

10 Spear MA, Jennings LC, Mankin HJ, Spiro IJ, Springfield DS, Gebhardt MC, Rosenberg AE, Efird JT and Suit HD: Individualizing management of aggressive fibromatoses. Int J Radiat Oncol Biol Phys 40(3): 637-645, 1998. PMID: 9486614. DOI: $10.1016 / \mathrm{s} 0360-3016(97) 00845-6$

11 le Grange F, Cassoni AM and Seddon BM: Tumour volume changes following pre-operative radiotherapy in borderline resectable limb and trunk soft tissue sarcoma. Eur J Surg Oncol 40(4): 394-401, 2014. PMID: 24534361. DOI: 10.1016/j.ejso. 2014.01.011

12 Schoot RA, McHugh K, van Rijn RR, Kremer LC, Chisholm JC, Caron HN and Merks JH: Response assessment in pediatric rhabdomyosarcoma: Can response evaluation criteria in solid tumors replace three-dimensional volume assessments? Radiology 269(3): 870-878, 2013. PMID: 23985275. DOI: 10.1148/radiol.13122607

13 Prasad SR, Jhaveri KS, Saini S, Hahn PF, Halpern EF and Sumner JE: CT tumor measurement for therapeutic response assessment: Comparison of unidimensional, bidimensional, and volumetric techniques initial observations. Radiology 225(2): 416-419, 2002. PMID: 12409574. DOI: 10.1148/radiol. 2252011604

14 Jaffe CC: Measures of response: RECIST, WHO, and new alternatives. J Clin Oncol 24(20): 3245-3251, 2006. PMID: 16829648. DOI: $10.1200 /$ JCO.2006.06.5599
15 Sundaram M, McGuire MH and Schajowicz F: Soft-tissue masses: Histologic basis for decreased signal (short T2) on T2weighted MR images. AJR Am J Roentgenol 148(6): 1247-1250, 1987. PMID: 3034013. DOI: 10.2214/ajr.148.6.1247

16 Braschi-Amirfarzan M, Keraliya AR, Krajewski KM, Tirumani $\mathrm{SH}$, Shinagare AB, Hornick JL, Baldini EH, George S, Ramaiya $\mathrm{NH}$ and Jagannathan JP: Role of imaging in management of desmoid-type fibromatosis: A primer for radiologists. Radiographics 36(3): 767-782, 2016. PMID: 27163593. DOI: 10.1148/rg.2016150153

17 Ballo MT, Zagars GK and Pollack A: Radiation therapy in the management of desmoid tumors. Int J Radiat Oncol Biol Phys 42(5): 1007-1014, 1998. PMID: 9869223. DOI: 10.1016/s03603016(98)00285-5

18 Acker JC, Bossen EH and Halperin EC: The management of desmoid tumors. Int J Radiat Oncol Biol Phys 26(5): 851-858, 1993. PMID: 8344854. DOI: 10.1016/0360-3016(93)90501-1

19 Santti K, Beule A, Tuomikoski L, Rönty M, Jääskeläinen AS, Saarilahti K, Ihalainen $\mathrm{H}$, Tarkkanen $\mathrm{M}$ and Blomqvist C: Radiotherapy in desmoid tumors: Treatment response, local control, and analysis of local failures. Strahlenther Onkol 193(4): 269-275, 2017. PMID: 28044201. DOI: 10.1007/s00066-0161091-8

20 Bocale D, Rotelli MT, Cavallini A and Altomare DF: Antioestrogen therapy in the treatment of desmoid tumours: a systematic review. Colorectal Dis 13(12): e388-e395, 2011. PMID: 21831172. DOI: 10.1111/j.1463-1318.2011.02758.x 